\title{
Influence of the unsaturated photoinitiators kind on the properties of uv-crosslinkable acrylic pressure-sensitive adhesives
}

\author{
Zbigniew Czech ${ }^{1}$, Agnieszka Kowalczyk ${ }^{1}$, Karolina Górka ${ }^{1}$, Urszula Głuch ${ }^{1}$, Lu Shao ${ }^{2}$, \\ Jolanta Świderska ${ }^{3}$
}

${ }^{1}$ West Pomeranian University of Technology in Szczecin, Poland

${ }^{2}$ Harbin Institute Technology, Harbin, China

${ }^{3}$ Non-Public Health Center, Szczecin, Poland

"Corresponding author: e-mail: e-mail:psa_czech@wp.pl

\begin{abstract}
UV-crossinkable pressure-sensitive adhesives (PSA) materials are called, in the adhesives trade photoreactive self-adhesive. UV-crosslinkable PSAs are designed after the UV-initiated crosslinking reaction to stick to almost any surface by a simple contact under light pressure. This special class of adhesives does not undergo any physical transformation or chemical reaction during the bonding process. Because of the rheological properties the adhesive must be finely tuned for the application, combining a carefully chosen polymer architecture and monomer composition with the proper addition of small additives called photoinitiators. The best way is using the unsaturated copolymerizable photoinitiators and their direct incorporation into polymer chain during the polymerization process. Progress in the coating technology and the development of novel photoreactive acrylic adhesives will open the door to new applications and an extended market penetration of UV-crosslinkable acrylic adhesive raw materials containing unsaturated copolymerizable photoinitiators incorporated into the polymer backbone. Photoreactive UV-crosslinkable acrylic PSA are characterized by good tack, good adhesion, excellent cohesion and very low shrinkage.
\end{abstract}

Keywords: pressure-sensitive adhesive, photoreactive, UV-crosslinking, tack, peel adhesion, shear strength, shrinkage.

\section{INTRODUCTION}

Among the different classes of adhesives, pressure-sensitive adhesives (PSA) are perhaps the most common type found in consumer products. Self-adhesive tapes, labels and films of all kinds are ubiquitous in every-day life. However, until recently, the understanding of the materials science and engineering of PSA and, in particular, the specific role played by the different components in them was very limited outside of the companies involved in their manufacture, and the interested reader had to refer to general technological texts ${ }^{1-2}$.

In the word of PSAs business acrylics make up about $40 \%$ of the amount. For the acrylic segment about $25 \%$ is solvent-borne and the rest is de facto primarily water-borne. Very small parts of about maximum 3-5\% are solvent-free acrylic systems. Typical solvent-borne photorective UV-crosslinkable PSAs have successfully been used for labels, tapes, films and medical products for several years. Although there is only a limited range of UV-crosslinkable raw materials available, formulation of these materials has opened a wide range of new synthesized self-adhesives ${ }^{3-4}$. The today known UV-crosslinkable solvent-borne acrylic systems contain photoreactive groups as an unsaturated photoinitiator incorporated into the polymer chain during PSA synthesis. Photoreactive solvent-borne acrylic PSA are not commercially available on the market for the production of pressure-sensitive adhesive tapes, labels and medical products.

After being coated on the carrier and drying in the drying canal, the acrylic film is crosslinked by UV-irradiation using commercial available UV lamps to become the adhesive performance as required. Standard mercury medium pressure vapor lamps include the right wave length bands in their emission spectrum in the area UV-C between 220 and $280 \mathrm{~nm}$ necessary for an efficient
UV- initiated crosslinking reaction. This phenomenon is the result of the crosslinking reaction that takes place when the polymer layer is exposed to UV radiation. A photoinitiator is used to absorb the UV-radiation and generate upon clavege or upon intermolecular reaction the reactive species, free radicals, that will initiate the UV-crosslinking. A unique advantage of the UV-crosslinking technology is to provide a precise temporal and spatial control of the setting process which will occur on order, selectively in the illuminated areas. Such performance, together with cost and environmental consideration, are the main reasons why UV-crosslinkable adhesives are being increasingly used and continue to attract attention in various sectors, as shown by the numerous patents taken recently on nove applications of this technology. A crucial factor in developing the high performance UV-crosslinkable acrylic PSA is obviously to ensure an excellent adhesion into the various types of supports ${ }^{5-8}$.

The limitation of the UV-technology in PSA applications results from the fact that crosslinking of the photoreactive occurs only in the illuminated areas so that at least one part of the assembly needs to be transparent to UV radiation?. The quantity of radiation energy to which the adhesive layer is exposed is expressed by the UV-dose, measured in $\mathrm{mJ} / \mathrm{cm}^{2}$. The UV-dose can be controlled by adjusting the power of the lamps and speed at which the substrate is passed under the lamps in the production plant ${ }^{10-11}$.

The crosslinking mechanism of photoreactive acrylic PSAs, containing photoreactive benzophenone derivatives incorporated into polymer backbone has been thoroughly investigated. It is presented schematically (Fig. 1$)^{2}$. During UV exposure the intermolecular benzophenone derivative $\mathrm{H}$-abstractor structures are excited and react by hydrogen abstraction with the neighboring tertiary carbon atom positions of the polymer side chains. To produce the 


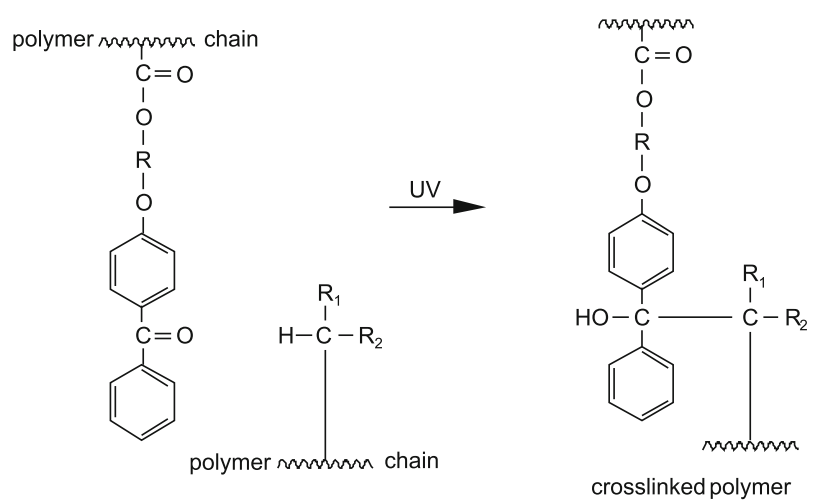

Figure 1. The UV initiated crosslinking reaction of acrylic PSA ( $\mathrm{R}=$ alkylene, $\mathrm{R}_{1}, \mathrm{R}_{2}=$ alkyl groups)

radicals that are necessary for the crosslinking reaction in the adhesive film, the photoreactive ABP groups have to absorb the UV radiation in such a way that special transitions in the orbits of electrons are generated ${ }^{12-14}$.

The limitations of the UV-crosslinking include the high cost of unsatured copolymerizable photoinitiators, not availability on the market, the non FDA status, significant absorption in the shorter wavelength regions of the UV spectrum as does the acrylic PSA, the penetration limitations, and the non-linearity with line speeds ${ }^{15-16}$.

\section{EXPERIMENTAL}

\section{Synthesis of photoreactive solvent-free acrylic PSA}

The following experiments were performed to investigate the influence of selected unsaturated photoinitiators type II (hydrogen abstractors) on the evaluated properties of synthesized acrylic hotmelts. Acrylic PSA have been synthesized in organic solvent ethyl acetate at $78^{\circ} \mathrm{C}$ in the presence of 0.1 wt.\% radical starter AIBN using the monomers mixture composed 95 wt.\% 2-ethylhexyl acrylate (2-EHA) and 5 wt.\% acrylic acid (AA) and copolymerizable benzophenone photoinitiators, such as 4-acryloyloxy benzophenone (ABP), 4-acryloyloxyethoxy benzophenone (AEBP), 4-acryloyloxybutoxy benzophenone (ABBP) and 4-acryloyloxyhexoxy benzophenone (AHBP) and 4-acryloyloxyoctoxybenzophenone (AOBP) with different length of organic spacer. The copolymerizable photoinitiators have been incorporated into the polymer backbone in concentrations between 0.05 and

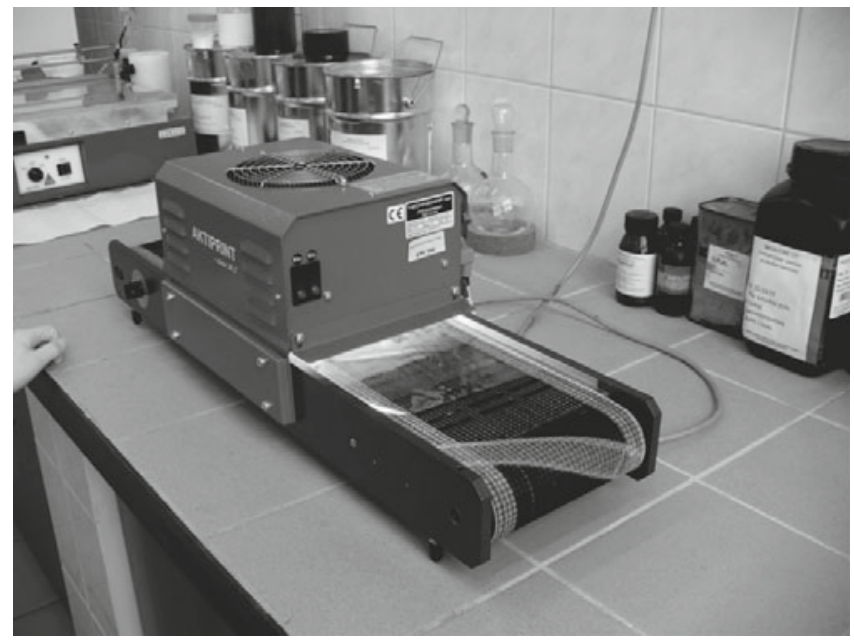

Figure 2. UV lamp with transmission belt
1.5 wt. \% according to monomer mixture amount. They are available from POLY-CHEM Company (Germany). All monomers, radical starter AIBN and ethyl acetate were available from BASF (Germany).

\section{Coating and UV-crosslinking}

The synthesized acrylic PSA were coated with $60 \mathrm{~g} / \mathrm{m}^{2}$ coat weight on the polyester film and dried for $10 \mathrm{~min}$ in a dry canal at $105^{\circ} \mathrm{C}$. The dry self-adhesive acrylic films were crosslinked using the UV lamp Aktiprint-Mini 18-2 from Technigraf (Fig. 2) by different UV-dose and different UV crosslinking time. The UV-doses in $\mathrm{mJ} / \mathrm{cm}^{2}$ were measured using the UV-integrator from Technigraf. Tack, peel adhesion, shear strength and the shrinkage of UV crosslinked self-adhesive layers were tested.

\section{Evaluation of PSA properties}

The influence of the UV-crosslinking is usually determined in relation to the UV-dose and UV-crosslinking time versus the important self-adhesive properties, such as: tack (initial adhesion), peel adhesion (adhesion), shear strength (cohesion) and shrinkage. The first three $t$ properties were determined by the standard A.F.E.R.A. (Association des Fabricants Europeens de Rubans Auto-Adhesifs) procedures. The exact details can be found in AFERA 4015 (tack), AFERA 4001 (peel adhesion) and AFERA 4012 (shear strength). The administrative address: 60, rue Auber-94408 Vitry Sur Seine Cedex, France. By shrinkage evaluation of synthesized acrylic PSA they have been coated on the siliconized paper and after UV crosslinking transferred directly onto the PVC film [12]. Shrinkage presents the percentage or millimeter change of the dimensions of the PVC foil covered with PSA after PSA crosslinking and attached to the glass after keeping it for 4 weeks at the temperature of $60^{\circ} \mathrm{C}$. With shrinkage greater than $0.5 \%$ or greater than 0.5 $\mathrm{mm}$ other properties were neglected.

\section{RESULTS AND DISCUSSION}

\section{Molecular weight versus photoinitiator kind and con- centration}

The molecular weight studies $\left(\mathrm{M}_{\mathrm{W}}-\right.$ weight average molecular weight, $M_{n}-$ number average molecular weight and $\mathrm{P}_{\mathrm{d}}-$ polydispersity) were performed in tetrahydrofurane with a liquid chromatograph LaChrom system: RI Detector L-7490 and LaChrom UV Detector L-7400 from Merck-Hitachi, equipped with a PLgel $10^{6} \AA$ A column from Hewlett-Packard.

The influence of evaluated copolymerizable photoinitiators on molecurar weight $\mathrm{M}_{\mathrm{W}}$ of synthesized acrylic PSA is shown in the Figure 3.

From the investigated experimental results the following conclusions can be inferred that a correlation was found between concentration of the investigated unsaturated copolymerizable photoinitiator type II and the molecular weights $M_{w}$ and $M_{n}$ of the synthesized acrylic PSA. The increase of the photoinitiator concentration increases the molecular weight $\mathrm{M}_{\mathrm{W}}$ and decreases the molecular weight $\mathrm{M}_{\mathrm{n}}$ of synthesized photoreactive acrylic PSA. The highest evaluated molecular weights $M_{W}$ and $M_{n}$ of acrylic PSA have been observed for the adhesive which contain 


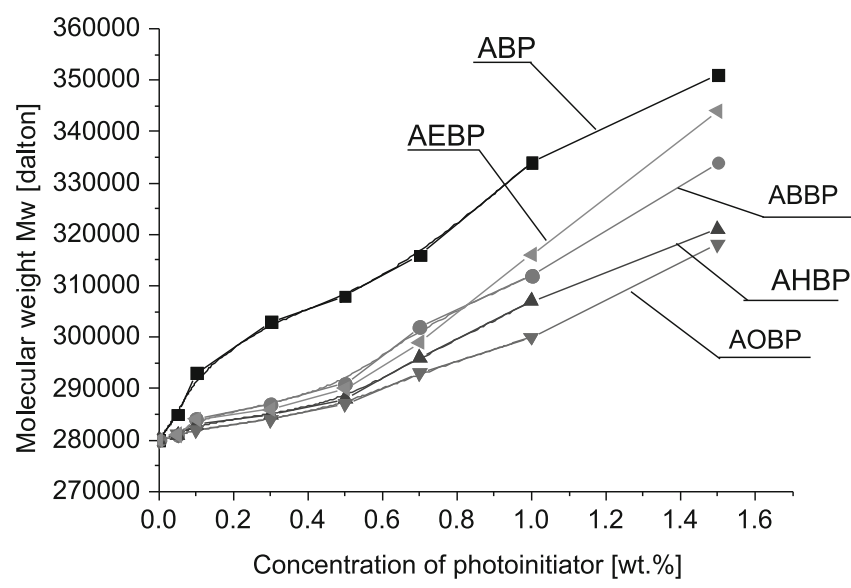

Figure 3. Molecular weight $\mathrm{M}_{\mathrm{w}}$ of acrylic PSA versus type and concentration of photoinitiator

4-acryloyloxy benzophenone (ABP) in the polymer chain. With a longer organic spacer between acryloyloxy group and chromophoric benzophenone group the molecular weight $\mathrm{M}_{\mathrm{W}}$ of acrylic PSA has been reduced (Fig. 3). The lowest molecular weight $\mathrm{M}_{\mathrm{w}}$ was in the case of the copolymerizable 4-acryloyloxyoctoxybenzophenone (AOBP) observed.

\section{Influence of kind and concentration of copolymerizable photoinitiator on tack}

Tack has been one of the favorite subjects of theorists over many years, often resulting in the derivation of complex formulae in an attempt to explain the property. Nevertheless, tack is still considered and rated by many as how well a pressure-sensitive adhesive sticks to the finger following only slight pressure and short dwell time. While in many cases this can be an approximate measure, this method is badly flawed in that it is highly subjective.

As it can be seen from the tack results recorded in Fig. 4, the most efficient UV crosslinking of the acrylic PSA (lowering of tack) will be observed for adhesives containing 4-acryloyloxy benzophenone (ABP) and 4-acryloyloxyethoxy benzophenone (AEBP).

Influence of kind and concentration of copolymerizable photoinitiator on peel adhesion

The effective photoinitiator concentration during the UV initiated crosslinking of acrylic PSA, for UV-dose of

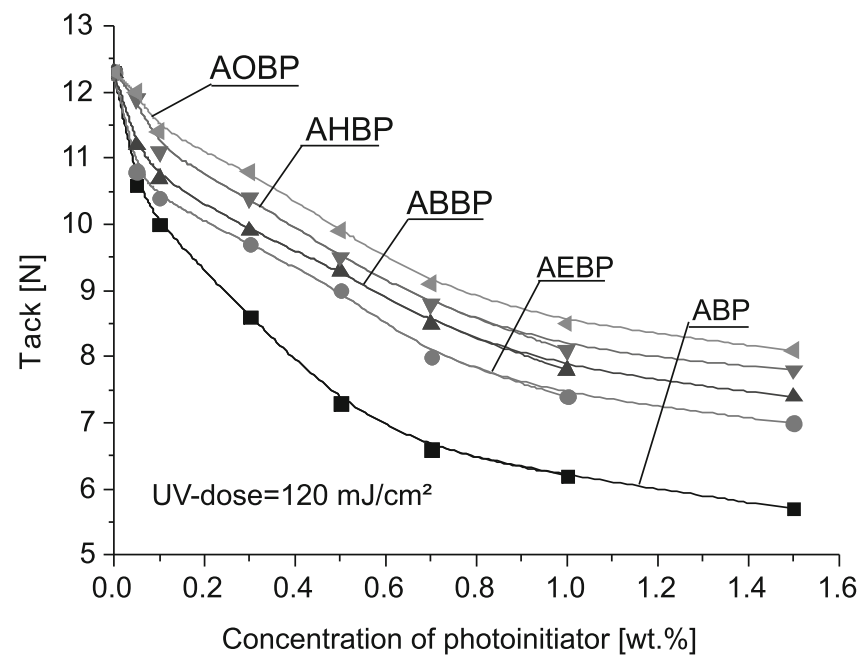

Figure 4. Tack of acrylic PSA versus type and concentration of photoinitiator

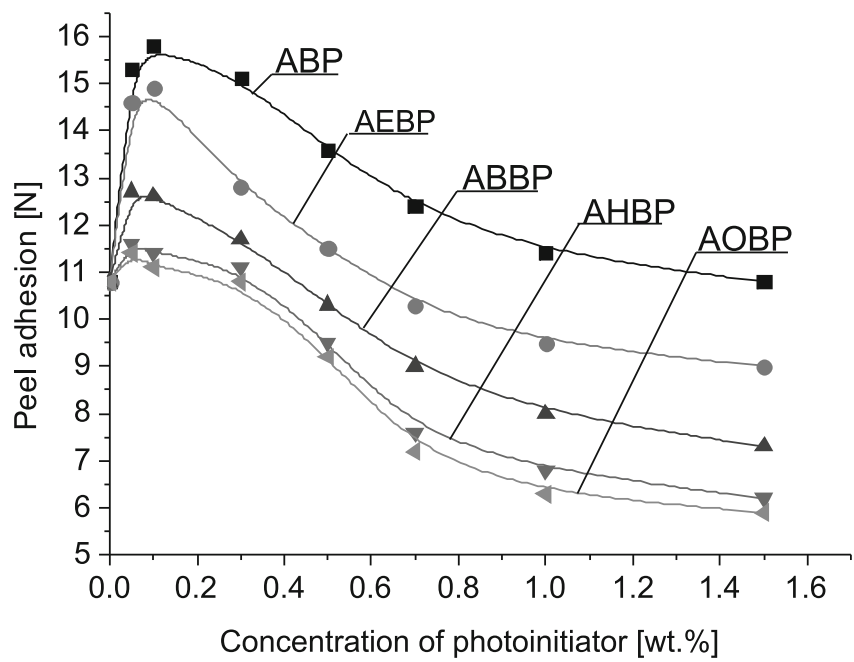

Figure 5. Peel adhesion of acrylic PSA versus type and concentration of photoinitiator

$120 \mathrm{~mJ} / \mathrm{cm}^{2}$, is recorded for the purpose of peel adhesion amendment. The maximum of peel adhesion value was observed for $0.1 \mathrm{wt}$. \% of copolymerizable photoinitiator for all evaluated acryloyloxy-benzophenones. Obviously, the increasing of the photoinitiator concentration above 0.1 wt.\% exerts a decisive effect on the peel adhesion decrease of UV-crosslinked adhesives (Fig. 5). The less reactive tested unsaturated photoinitiator moves the peel adhesion maximum values to the lower level, up with the rise of higher photoinitiator amounts.

Influence of of copolymerizable photoinitiator kind and concentration on PSA shear strength at $20^{\circ} \mathrm{C}$ and $70^{\circ} \mathrm{C}$

Typical shear resistance testing is performed with a controlled area of adhesive layer applied to a standard test surface. Because shear failure is the inability of the pressure-sensitive adhesive to resist a continuous stress, any task that is a measure of stress relaxation within the adhesive gives meaningful data. A high shear resistant adhesive will maintain the stress, while a poor shear resistant adhesive will relieve the stress quite rapidly.

Incorporation of unsaturated photoinitiators type II based on benzophenones into acrylic polymer structure influences strongly the shear strength properties of the UV-crosslinked acrylic PSA (Fig. 6). An increase of the concentration of the investigated photoinitiators produces, after UV exposure a higher network density, leading to higher cohesion in comparison with classical

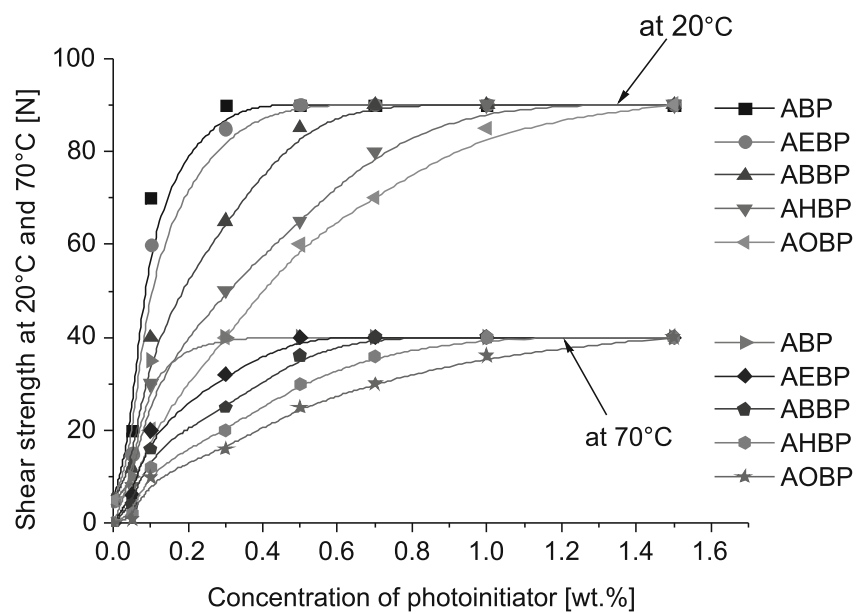

Figure 6. Shear strength of acrylic PSA at $20^{\circ} \mathrm{C}$ and $70^{\circ} \mathrm{C}$ versus type and concentration of photoinitiator 
conventional photoinitiator systems. The highest shear strength results were observed for about $0.3 \mathrm{wt} . \% \mathrm{ABP}$ and for $0.5 \mathrm{wt} \% \mathrm{AEBP}$ at $20^{\circ} \mathrm{C}$ and $70^{\circ} \mathrm{C}$. Both acryloyloxy-photoinitiators increased cohesion equally. For unsaturated copolymerizable photoinitiator 4-acryloyloxyoctoxybenzophenone (AOBP) with longest organic spacer the lowest shear strength level was noticed.

\section{Influence of kind and concentration of copolymerizable photoinitiator on shrinkage}

Before crosslinking, the molecules, which comprise the PSA acrylate are separated by their characteristic van der Waals radii. Upon crosslinking, these intermolecular distances are reduced due to the formation of covalent bonds between the monomers which produces the desired highly crosslinked PSA material. This reduction of intermolecular distances creates internal stress throughout the crosslinked network, which is manifested by reduced adhesion of the PSA adhesive to both the substrate and the object attached thereto.

Shrinkage presents the percentage or millimeter change of dimensions of the PVC foil coated with PSA after PSA crosslinking and attached to the steel, glass or aluminum after keeping it 4 weeks at temperature of $60^{\circ} \mathrm{C}$. With shrinkage greater than $0.5 \%$ or greater than $0.5 \mathrm{~mm}$ other properties were neglected ${ }^{13-15}$.

The influence of unsaturated photoinitiators type II on shrinkage by the same UV-dose $120 \mathrm{~mJ} / \mathrm{cm}^{2}$ was shown in Figure 7. In general, it can be said that the use of copolymerizable photoinitiators type II offers an interesting alternative to the very efficient method of reducing the shrinkage of acrylic PSA coated on PVC film. The best results with respect to shrinkage are observed in the case of 4-acryloyloxy benzophenone (ABP). The acrylic PSA containing $0.3 \mathrm{wt} . \% \mathrm{ABP}$ are characterized by very low shrinkage under $0.5 \%$. The lowering of the organic spacer in the structure of unsaturated photoinitiators has a negative influence on the shrinkage of UV-crosslinked acrylic PSA.

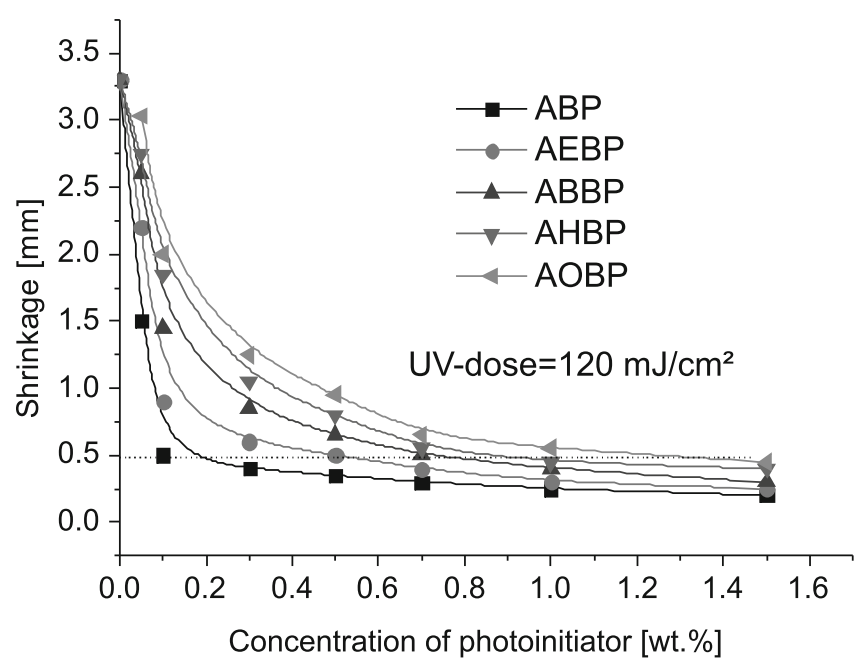

Figure 7. Shrinkage of acrylic PSA at $20^{\circ} \mathrm{C}$ and $70^{\circ} \mathrm{C}$ versus type and concentration of photoinitiator

\section{CONCLUSIONS}

The relevant properties of crosslinking solvent-borne acrylic PSA like tack, peel adhesion, shear strength and shrinkage have been evaluated according to test procedures established in the industry. Each individual property was determined as an average number derived from three measurements. In the case of major deviations the measurement was repeated. Solvent-borne acrylic PSAs with high performance being used in the PSA-technology shall be distinguished by very high shear strength $\left(120 \mathrm{~N}\right.$ at $20^{\circ} \mathrm{C}, 40 \mathrm{~N}$ at $\left.70^{\circ} \mathrm{C}\right)$. Furthermore for PVC application, shrinkage lower than $0.5 \%$, a high tack and a maximum peel adhesion are a must.

The research and development in the area of novel high quality photoreactive hotmelts acrylic PSA includes adhesive containing the unsaturated copolymerizable photoinitiators type II. The balance between UV- and PSA-technology is a very important factor in the manufacturing of high efficiency photoreactive acrylic PSA systems. The novel UV crosslinkable acrylic PSA can overcome the challenge of fulfilling the demands of removable applications. Either by formulation, by application, by UV-crosslinking level or by the combination of all industrial important parameters, the customer can achieve tailor-made solutions to be innovative and competitive for the future. The properties of the acrylic PSA can be adjusted right up to the crosslinking stage there is currently no such thing as a standard UV-crosslinkable acrylic PSA. Because chemical reaction takes place during crosslinking, a good understanding of the process and chemistry and how these two interact is needed to make a consistent product. From the investigated copolymerizable acryloyloxy-photoinitiators, the generally best performances of UV-crosslinked acrylic PSA were achieved by use of $\mathrm{H}$-abstractor 4-acryloyloxy benzophenone (ABP). The ABP was undoubtedly the most efficient photoinitiator among all the tested acryloyloxy-photoinitiators. 4-acryloyloxy benzophenone (ABP) is a very efficient copolymerizable photoinitiator. Already between 0.1 to 0.3 wt.\% of ABP is sufficient to reach a peel adhesion maximum and to reach a very high cohesion of $90 \mathrm{~N}$. The further increasing of ABP concentration decreases tack and peel adhesion of UV-crosslinked acrylic PSA, and simultaneously improves their shear strength tremendously. Novel UV-crosslinkable acrylic hotmelt PSA combines the economic advantages of the hotmelt coating technology with the high performance characteristics of the acrylic chemistry, including an excellent aging resistance, optical transparency and heat resistance. They can be used for the manufacturing of medical products as plaster, self-adhesive hydrogels, self-adhesive electrodes and wound dressing.

\section{LITERATURE CITED}

1. Czech, Z., (1999). Crosslinking of pressure-sensitive adhesives based on acrylics, Poland: Szczecin University of Technology.

2. Benedek, I., (2006). Developments in pressure-sensitive products, USA: Istvan Benedek, Taylor \& Francis a CRC Press Book.

3. Wicks, Z.W., Jones, F.N., Pappas, S.P. \& Wicks, D.A., (2007). Organic coatings, USA: Wiley, New Jersey.

4. Czech, Z. \& Butwin, A. (2010). Replacement of UV-crosslinkable acrylic pressure-sensitive adhesives hotmelts by warmmelts and low viscosity systems cotable at room temperature: 35 . Munich Adhesives and Finishing Symposium, 25-27 October 2010 (pp. 167-177), Munich, Germany.

5. Czech, Z., Kowalczyk, A., Kabatc, J. \& Świderska, J., (2012). UV-crosslinkable acrylic pressure-sensitive adhesives 
for industrial application, Polym. Bull., in press , DOI 10.1007/ s00289-012-0725-y.

6. Creton, C.; (2003). Pressure-sensitive adhesives: A introductory course. Material_Research Society Bulletin, June (pp. 434-439).

7. Czech, Z., (2004). Development of solvent-free pressure-sensitive acrylics, Int. J. Adhes. Adhes., 24 , 119-125, DOI: 10.1016/j.ijadhadh.2003.07.001.

8. Czech, Z., Butwin, A. \& Ortyl, J. (2010). Ecological solvent-free photoreactive pressure-sensitive adhesives based on acrylics: $4^{\text {th }}$ International seminar Modern Polymeric Meterials for Emvironmental Applications, 1-3 December 2010 (pp. 61-72), Krakow, Poland.

9. Czech, Z. \& Butwin, A., (2010). UV-crosslinkable warm-melt pressure-sensitive adhesives based on acrylics, Pol. J. Chem. Technol. 12 (4), 59-62, DOI: 10.2478/v10026-010-0051-9.

10. Czech, Z., Butwin, A. \& Kabatc, J. (2011). Photoreactive UV-crosslinkable acrylic pressure-sensitive adhesives containing type-II photoinitiators, Eur. Polym. J. 47, 225-229, DOI: 10.1016/j. eurpolymj.2010.11.002.

11. Czech, Z. \& Butwin, A., (2011). Development of photoreactive UV-crosslinkable solvent-free acrylic pressure-sensitive adhesives coated at room temperature and used for removable and repositionable self-adhesives materials, Pol. J. Chem. Technol., 13, (1), 31-34, DOI: 10.2478/v10026-011-0006-9.

12. Czech, Z. \& Kowalczyk, A. (2011). Adhesives: Types, Mechanics and Applications, J.S. Doyle and R.C.O' Quinn (Eds.), Pressure-sensitive adhesives (pp. 47-69), Nova Science Publishers, Inc.

13. Czech, Z., Kowalczyk, A. \& Świderska, J. (2011). Quality Control,,I. Akyar, Publisher InTech (Eds), Pressure-sensitive adhesives for medical applications (pp. 309-332).

14. Czech, Z. \& Kurzawa, R. (2007). Acrylic pressure-sensitive adhesives for transdermal drug delivery systems, J. Appl. Polym. Sci. 106, 2398-2404, DOI: 10.1002/app.26751.

15. Czech, Z., Wróblewska, A., Meissner, E. \& Kurzawa, R. (2007). Pressure-sensitive adhesives for transdermal drug delivery systems, Conference: Surfactants and dispersant systems in theory and practice (Surfaktanty i układy zdyspergowane w teorii i praktyce) SURUZ, May 22-24 (pp. 443-446), Książ, Poland

16. Tauber, A., Scherzer, T., Weiss I. \& Mehnert, R. (2002), Waterborne acrylic - epoxy coatings, J. Coating Technol., 74, 41-47, DOI: 10.1007/BF02720162. 